\title{
ROLANDO CHUAQUI KETTLUN
}

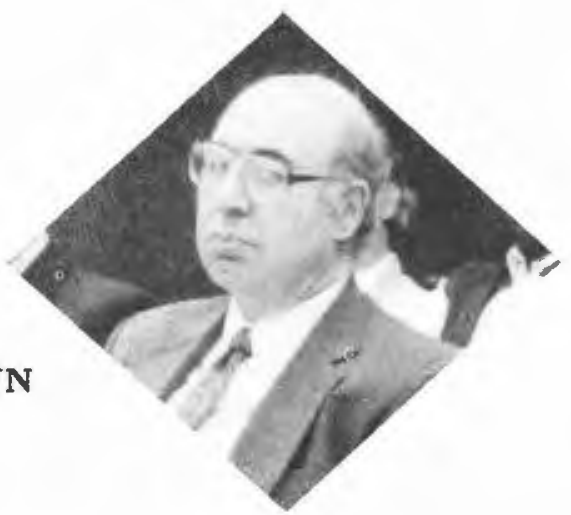

Proyecciones rinde homenaje al profesor ROLANDO CHUAQUI KETTLUN, miembro de su comité Editor, fallecido prematuramente el 23 de abril de 1994 en Santiago de Chile.

Rolando Chuaqui nació en Santiago el 30 de diciembre de 1935. Estudió Medicina en la Universidad de Chile, titulándose de Médico Cirujano en 1960. Preocupado desde muy temprano por el carácter aleatorio del diagnóstico médico y buscando una formulación más lógica para los razonamientos involucrados, viajó a perfeccionarse a los Estados Unidos. Alli evolucionó hacia el estudio de la Lógica y de las Matemáticas, completando estudios de doctorado en la Universidad de California, Berkeley, en Lógica y Metodología de la Ciencia en el año 1965, bajo la dirección del eminente lógico y matemático polaco Alfred Tarski.

De regreso a Chile, ese mismo año 1965 se incorporó al Departamento de Matemática de la naciente Facultad de Ciencias de la Universidad de Chile, contribuyendo entusiastamente a su desarrollo hasta 1969, año en que ingresó a la Pontificia Universidad Católica de Chile donde permaneció hasta su muerte.

Su actividad científica es abundante. Fué profesor e investigador visitante en la Universidad de California, Los Angeles, 1967-1968, Institute for Advanced Study, Princeton, 1969-1970, Universidad de Sao Paulo, agosto 1971 y febrero-marzo 1982, Universidad de California, Berkeley, 1973-1974, Universidad Stadual de Campinas, Brasil, marzo a julio de 1976, de 1977 y 1978, Universidad de Stanford, 1984 y 1986-89, San José States University, California, 1986-1989. Obtuvo también la beca Guggenheim para una estadía en Stanford en 1984. 
La excelencia académica que hoy exhibe la Facultad de Matemática de la Pontificia Universidad Católica de Chile debe mucho al profesor Chuaqui. Basta recordar que fue el primero en conducir estudios de doctorado en Matemática en Chile. Dos libros y más de 50 publicaciones en revistas especializadas muestran parte de su quehacer.

La intensa labor por él realizada, tanto en el cultivo de la lógica, la matemática y la filosofía, como en las innumerables labores que asumió, ideó y dirigió para el desarrollo de la ciencia chilena le significaron merecidos reconocimientos en el país y en el extranjero. El profesor Chuaqui fué Decano de la Facultad de Matemática de la Pontificia Universidad Católica de Chile 1982-1983 y desde 1990, Miembro de Número de la Academia Chilena de Ciencias desde 1977 y su Vicepresidente desde 1991, Miembro Titular de la Academia de Ciencias de América Latina desde 1983 y Miembro Correspondiente de la Academia de Ciencias del Estado de Sao Paulo en Brasil y de la Academia Argentina de Ciencias Exactas y Naturales, desde 1982 y 1988 respectivamente.

Aún cuando su labor científica y de dirección académica fué enorme, son las características de su cálida personalidad las que resultan más destacadas para todos los que lo conocieron. Su disposición siempre amable para ayudar en las variadas circunstancias a todas las personas que conoció y su propósito constante de cultivar amistades permanentes y sinceras, es lo que hizo más dolorosa su prematura partida.

La Revista Proyecciones que edita el Departamento de Matemática de la Universidad Católica del Norte, en Antofagasta, tuvo el privilegio de contarlo como uno de sus editores más preclaros y sobresalientes. 